\title{
A auditoria e os procedimentos de amostragem nas instituições federais de ensino superior da região sul do Brasil: aspectos gerais e específicos ao ano de 2010
}

\section{Audit and sampling procedures in federal institutions of higher education of southern Brazil: general and specific to the year 2010}

Sueli Farias

Mestranda pelo Programa de Pós-Graduação em Contabilidade pela Universidade Federal de Santa Catarina

Endereço: Servidão Mai Farias, 2.402, bairro Rio Tavares

CEP: 88.048-155 - Santa Catarina/SC - Brasil

E-mail: ninafarias_22@ hotmail.com

Telefone: (48) 8428-0150

\section{Juliana Pires Schulz}

Mestranda pelo Programa de Pós-Graduação em Administração Universitária pela

Universidade Federal de Santa Catarina

Endereço: Rua Apóstolo Paschoal, 759 - apto. 101, bairro Canasvieiras

CEP: 88.054-101 - Florianópolis/SC - Brasil

E-mail: schulzjuliana@hotmail.com

Telefone: (48) 9119-3762

\section{Rita Lucia Bellato}

Especialista em Administração, Gestão Pública e Políticas Sociais pela Faculdade Dom Bosco Endereço: Rua Capitão Romualdo de Barros, 965 - apto. 205, bloco D, bairro Carvoeira CEP: 88040-600 - Florianópolis/SC - Brasil

E-mail: ritaluciasc@ hotmail.com

Telefone: (48) 9903-3962

\section{Luiz Alberton}

Doutor em Engenharia de Produção pela Universidade Federal de Santa Catarina

Docente do Programa de Pós-Graduação em Contabilidade da Universidade Federal de Santa

Catarina

Endereço: Departamento de Ciências Contábeis - Centro Sócio-Econômico -

Universidade Federal de Santa Catarina, Trindade, Florianópolis, SC - CEP 88040-970.

E-mail: alberton@cse.ufsc.br

Telefone: (48) 9948-9014

Artigo recebido em 13/06/2012. Revisado por pares em 08/08/2012. Reformulado em 06/09/2012. Recomendado para publicação em 05/10/2012 por Sandra Rolim Ensslin (Editora Científica). Publicado em 14/12/2012. 


\title{
Resumo
}

O objetivo deste trabalho é pesquisar o funcionamento da auditoria e os procedimentos de amostragem nas Instituições Federais de Ensino Superior (IFES) da região Sul do Brasil. A metodologia caracteriza-se como predominantemente quantitativa, além de constituir um levantamento. De modo geral, a área de Gestão de Suprimento de Bens e Serviços foi mais frequentemente auditada. Especificamente no ano de 2010, os métodos de amostragem aleatória simples, sistemática e Tabela Philips foram os mais utilizados, bem como a seleção não estatística. Também se verificou que algumas subáreas não foram auditadas, como, por exemplo, Bens Intangíveis e Capacitação e Desenvolvimento.

Palavras-chave: Contabilidade governamental. Auditoria interna. IFES. Amostragem.

\begin{abstract}
The objective of this study is to investigate the functioning of the audit and sampling procedures in Federal Institutions of Higher Education (IFES) in southern Brazil. The methodology is characterized as predominantly quantitative, besides constituting a survey. In general, the area of Supply Management of Goods and Services was more often audited. Specifically in 2010, the methods of systematic simple random sampling and Philips Table were the most used, as well the non- statistical selection. It was also found that some subareas were not audited, for example, Intangible Assets and Training and Development.
\end{abstract}

Keywords: Governmental accounting. Internal auditorship. IFES. Sampling.

\section{Introdução}

A exigência de que os recursos públicos sejam controlados torna a auditoria governamental uma área de relevância dentro do sistema de gestão pública. Desse modo, considerando que a Contabilidade Pública tem por objetivo registrar os atos e fatos que afetam ou possam vir a afetar o patrimônio público, a auditoria, nesse contexto, é utilizada para validar e confirmar se os registros feitos encontram-se ou não em conformidade com os controles contábeis e administrativos voltados para a Administração Pública.

Nas entidades públicas federais, o Controle Externo é exercido pelo Poder Legislativo, com o auxílio do Tribunal de Contas da União (TCU); e o Controle Interno, pelo sistema de Controle Interno de cada Poder (art. 70, CF/88). Segundo Peter e Machado (2009, p. 24), o Controle Interno trata da "prevenção e correção de erros ou desvios no âmbito de cada poder ou entidade da Administração Pública". Cabe, assim, à auditoria interna avaliar a boa gerência dos recursos públicos, observando os programas e as ações governamentais.

A Instrução Normativa (IN), n. 01, de 6 de abril de 2001, emitida pela Secretaria Federal de Controle Interno (SFCI), define auditoria interna como um "conjunto de procedimentos, tecnicamente normatizados, que funciona por meio de acompanhamento 
indireto de processos, avaliação de resultados e proposição de ações corretivas para os desvios gerenciais da entidade à qual está vinculada". Define, ainda, que a auditoria interna deve ser realizada por auditor incumbido especialmente para essa função, tendo como principal objetivo o assessoramento à alta administração da entidade, buscando agregar valor à gestão.

Visando facilitar o emprego dos procedimentos e técnicas de auditoria, a gestão pública está dividida em sete áreas: Controles da Gestão, Gestão Orçamentária, Gestão Financeira, Gestão de Recursos Humanos, Gestão Patrimonial, Gestão de Suprimento de Bens e Serviços, e Gestão Operacional (CHAVES, 2010).

Para a realização de auditoria em que o volume de elementos, setores e áreas é extenso, a técnica de amostragem se apresenta como uma forma apropriada para a execução dos procedimentos de auditoria. Nesse caso, segundo a IN 01/2001 e a Norma Brasileira de Contabilidade de Auditoria Independente (NBC TA) n. 530 - Amostragem em Auditoria, do Conselho Federal de Contabilidade (CFC), aprovada pela Resolução CFC 1.222, de 27 de novembro de 2009, a amostragem compreende a utilização de auditagem de parte da população a ser verificada, em que todos os itens possuem igual probabilidade de serem selecionados, adotando-se critérios que validem os resultados para toda a população baseados nos resultados encontrados para a amostra.

Desse modo, este trabalho tem por objetivo pesquisar o funcionamento da auditoria e os procedimentos de amostragem nas Instituições Federais de Ensino Superior (IFES) da região Sul do Brasil, em caráter geral e especificamente no ano de 2010 . A justificativa desta pesquisa pauta-se pela escassez de publicação de trabalhos na área pública, bem como pela relevância do tema, uma vez que se procura verificar como as unidades de auditorias internas das IFES executam suas atividades.

Cinco seções, além desta, fazem a composição deste estudo. A seção dois trata do referencial teórico acerca do tema estudado, e a seção três descreve o enquadramento e a metodologia empregada. A quarta seção apresenta a análise dos dados obtidos e, por fim, a quinta e última seção compreende as considerações finais acerca dos resultados.

\section{Referencial Teórico}

Para fundamentar o entendimento de como funciona e se realiza a auditoria nas IFES, serão abordados, a seguir, aspectos relacionados ao controle e à auditoria interna, à amostragem e às áreas de gestão pública.

\subsection{O Controle e a Auditoria Interna nas IFES}

Segundo Peter e Machado (2009, p. 24), os Controles Internos são constituídos por um "conjunto de atividades, planos, métodos e procedimentos interligados, utilizados com vistas a assegurar que os objetivos dos órgãos e entidades da Administração Pública sejam alcançados [...]". Em sentido geral, os Controles Internos devem ser realizados de forma a servirem de orientação, de maneira preventiva, à Administração Pública.

O Sistema de Controle Interno do Poder Executivo Federal, disposto por meio do Decreto n. 3.591/2000, visa avaliar a ação governamental e a gestão exercida pelos administradores públicos. $\mathrm{O}$ art. $2^{\circ}$ do referido Decreto dispõe sobre as finalidades do Sistema 
de Controle Interno, como, por exemplo, a de comprovar a legalidade e avaliar os resultados quanto à eficiência e eficácia nos órgãos e na Administração Pública.

Ainda, segundo esse mesmo Decreto, é de competência do Sistema de Controle Interno verificar a adequada aplicação dos recursos públicos por entidades de direito privado, exercer o controle das operações de crédito, além de apoiar o controle externo no exercício da missão institucional.

Além dessas prerrogativas, essa legislação ainda determina que seja organizada uma unidade de auditoria interna nas entidades da Administração Pública Federal Indireta, com o suporte necessário de recursos humanos e materiais, visando ao fortalecimento da gestão e à racionalização das ações de controle. Sendo assim, as auditorias internas, além de evidenciarem os Controles Internos, devem fornecer suporte para a gestão pública.

Embora as Normas de Auditoria Governamental (NAGs) tenham sido desenvolvidas no âmbito dos Tribunais de Contas com foco no controle externo, elas apresentam um conceito completo e objetivo acerca da auditoria governamental, quando dispõem que essa classificação diz respeito ao

exame efetuado em entidades da administração direta e indireta, em funções, subfunções, programas, ações (projetos, atividades e operações especiais), áreas, processos, ciclos operacionais, serviços, sistemas e sobre a guarda e a aplicação de recursos públicos por outros responsáveis, em relação aos aspectos contábeis, orçamentários, financeiros, econômicos, patrimoniais e operacionais, assim como acerca da confiabilidade do sistema de controle interno (SCI). É realizada por profissionais de auditoria governamental, por intermédio de levantamentos de informações, análises imparciais, avaliações independentes e apresentação de informações seguras, devidamente consubstanciadas em evidências, segundo os critérios de legalidade, legitimidade, economicidade, eficiência, eficácia, efetividade, equidade, ética, transparência e proteção do meio ambiente, além de observar a probidade administrativa e a responsabilidade social dos gestores da coisa pública (Instituto Rui Barbosa, 2010).

Segundo Humphrey (1991 apud Costa; Pereira; Blanco, 2006), existem três teorias que justificam a utilização de auditoria: a teoria da agência, do raciocínio econômico da análise do custo-benefício, e a teoria do interesse público. Esta última, quando aplicável à área pública, fundamenta-se no interesse público da função, ou seja, a presença de uma auditoria numa organização ou a ciência da existência de controles efetivos tem o poder de dissuadir práticas indesejáveis nessa área.

A Norma Brasileira de Contabilidade TI (NBC TI) 01 - Da Auditoria Interna, aprovada pelo Conselho Federal de Contabilidade, Resolução CFC 986, de 21 de novembro de 2003, dispõe:

A Auditoria Interna compreende os exames, análises, avaliações, levantamentos e comprovações, metodologicamente estruturados para a avaliação da integridade, adequação, eficácia, eficiência e economicidade dos processos, dos sistemas de informações e de controles internos integrados ao ambiente e de gerenciamento de riscos, com vistas a assistir à administração da entidade no cumprimento de seus objetivos.

A Auditoria Interna deve ser estruturada com procedimentos sob o enfoque técnico, de forma sistemática e disciplinada, de maneira a agregar valor para a entidade, auxiliar nos

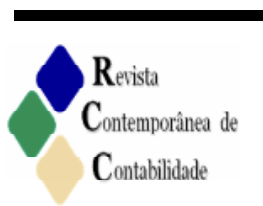


processos e controles internos, além de orientar em caso de não conformidade (NBC TI 01 986/2003).

As ações do Estado objetivam atender às necessidades mais prementes da sociedade, tais como segurança, saúde, educação, entre outros. Nesse sentido, várias são as áreas em que a Administração executa ações a fim de auxiliar o Estado no cumprimento dos seus objetivos. Segundo Chaves (2010, p. 34), as "atividades meio e fim, executadas ordenadamente e necessárias aos serviços públicos em geral, são denominadas de gestão pública”.

As áreas de Gestão de Recursos Humanos, Gestão Patrimonial e Gestão de Suprimento de Bens e Serviços, focos deste estudo, são descritas a seguir.

\section{2 Áreas de Gestão Analisadas}

Cada área de gestão possui suas especificidades, as quais, conforme Chaves (2010), são assim descritas:

Gestão de Recursos Humanos - A auditoria na área de Recursos Humanos deve analisar a contratação de pessoal desde o provimento do cargo público até a aposentadoria, verificando benefícios, adicionais, indenizações e afins.

Gestão Patrimonial - Nesta área, a auditoria deve analisar se a entidade possui o inventário dos bens físicos; verificar o estado de conservação dos bens; além de averiguar a responsabilidade por quaisquer extravios. Todos os bens devem ser registrados com seus respectivos termos de responsabilidade e, em caso de extravio, o servidor responsável deve fazer a comunicação imediata ao responsável para abertura de processo para apurar a causa e, se necessário, o ressarcimento ao erário.

Gestão de Suprimento de Bens e Serviços - Esta área é considerada bastante complexa, visto que possui "grande número de normativos, tornando sua análise uma tarefa que exige bastante conhecimento da jurisprudência da doutrina e do caso concreto" (CHAVES, 2010, p. 39).

De modo a evidenciar e facilitar o entendimento dessas áreas de gestão, no Quadro 1, são apresentadas, de forma sintetizada, outras características que as compõem.

Quadro 1 - Subáreas e assuntos específicos das áreas de Gestão de Recursos Humanos, Gestão Patrimonial e Gestão de Suprimento de Bens e Serviços

\begin{tabular}{|c|l|l|}
\hline Áreas & \multicolumn{1}{|c|}{ Subáreas } & \multicolumn{1}{|c|}{ Assuntos específicos } \\
\hline $\begin{array}{c}\text { Gestão de Recursos } \\
\text { Humanos }\end{array}$ & $\begin{array}{l}\text { *Movimentação; } \\
\text { *Remuneração; } \\
\text { *Benefícios e Vantagens; } \\
\text { *Indenizações; } \\
\text { *Capacitação e Desenvolvimento; } \\
\text { *Seguridade Social; e } \\
\text { *Regime Disciplinar. }\end{array}$ & $\begin{array}{l}\text { Provimentos, vacâncias, reajustes e limites } \\
\text { remuneratórios, ajuda de custo, incentivos } \\
\text { funcionais, aposentadoria, processos de } \\
\text { sindicância, entre outros. }\end{array}$ \\
\hline \multirow{3}{*}{ Gestão Patrimonial } & $\begin{array}{l}\text { *Inventários Físicos e Financeiros; } \\
\text { *Bens Imobiliários; }\end{array}$ & *Recursos Naturais; \\
& *Meios de Transportes; \\
& *Bens Móveis e Equipamentos; \\
& *Bens Agropecuários; \\
& *Acervo de Bens Culturais; \\
& *Bens Intangíveis; e \\
*Investimentos Permanentes. & $\begin{array}{l}\text { Sistemas de controle patrimonial, baixas } \\
\text { de bens imobiliários, avaliação de recursos } \\
\text { naturais, avaliação de bens móveis e } \\
\text { equipamentos, avaliação de investimentos } \\
\text { permanentes, entre outros. }\end{array}$ \\
\end{tabular}




\begin{tabular}{|c|c|c|}
\hline $\begin{array}{l}\text { Gestão de Suprimento de } \\
\text { Bens e Serviços }\end{array}$ & $\begin{array}{l}\text { *Processos Licitatórios; } \\
\text { *Contratos de Obras, Compras e } \\
\text { Serviços; } \\
\text { *Convênios de Obras e Serviços; } \\
\text { *Gerenciamento de Estoques e } \\
\text { Contratos de Franquias, e } \\
\text { *Concessão ou Permissão. }\end{array}$ & $\begin{array}{l}\text { Formalização legal dos processos } \\
\text { licitatórios, alterações contratuais, } \\
\text { prestação de contas, sistemas de controles } \\
\text { de estoque, resultado de contratações, } \\
\text { entre outros. }\end{array}$ \\
\hline
\end{tabular}

Fonte: Adaptado de Chaves (2010).

Dentre as áreas apresentadas, a Gestão de Suprimento de Bens e Serviços, segundo Chaves (2010, p. 39), "[...] é a área que mais sofre com falhas e/ou irregularidades (corrupção) na Administração Pública" e, por consequência, é a área onde se concentra o maior número de auditorias.

\subsection{Amostragem em Auditoria}

Segundo a NBC TA 530/2009, a amostragem em auditoria significa a "aplicação de procedimentos de auditoria em menos de $100 \%$ dos itens de população relevante para fins de auditoria, de maneira que todas as unidades de amostragem tenham a mesma chance de ser selecionadas [...]", e, assim, segundo as características encontradas, o auditor forma uma opinião sobre toda a população.

Para Chaves (2010), amostragem é o processo em que os dados de um conjunto, denominado universo ou população, são obtidos por meio do exame dessa parte denominada amostra. Como se observa, a amostragem consiste no processo de obter dados que sejam representativos o suficiente, a fim de proporcionar conclusões válidas para toda a população por meio da análise de parte do universo (amostra). No entendimento de Boyton, Johnson e Kell (2002, p. 506), "a unidade de amostragem deve ser compatível com o objetivo e os procedimentos de auditoria a serem executados".

Da mesma forma, a utilização da amostragem também tem como objetivo a correta realização do trabalho ao considerar custo/benefício, no sentido de tornar o trabalho viável. O art. 14 do Decreto-Lei n. 200, de 25 de fevereiro de 1967, dispõe, em relação ao controle, que "o trabalho administrativo será racionalizado mediante simplificação de processos e supressão de controles que se evidenciarem como puramente formais ou cujo custo seja evidentemente superior ao risco".

A decisão dos auditores de utilizar o procedimento de amostragem, de acordo com Coopers (1985), parte de motivos como: adquirir ou ampliar o conhecimento da natureza do saldo de uma conta ou transação; entender, de forma mais precisa, o projeto e funcionamento do sistema contábil e dos procedimentos de controle; inspecionar detalhes de itens individualmente significativos, entre outros.

A utilização de amostragem é um procedimento muito utilizado nas instituições, privadas ou públicas; no entanto o auditor precisa estar atento para o risco de que a amostra não seja representativa da realidade (SANTOS; DINIZ; CORRAR, 2005).

Em auditoria, a amostragem pode ser classificada em estatística ou não estatística. A amostragem estatística, segundo a NBC TA 530, caracteriza-se pela seleção de amostra com métodos científicos, utilizando a teoria da probabilidade ou regras estatísticas, e é recomendada quando os itens de uma população possuem características homogêneas.

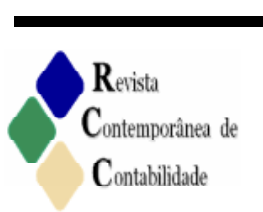


Por outro lado, a amostragem não estatística ocorre quando a amostra é determinada sem considerar seleção científica; é realizada de acordo com a experiência, subjetividade e conhecimento do auditor (CUNHA; BEUREN, 2006; KROENKE et al., 2008).

Dentre os diversos métodos de amostragem, o Quadro 2 apresenta aqueles utilizados no questionário da pesquisa.

Quadro 2 - Métodos de seleção de amostra

\begin{tabular}{|c|c|}
\hline Método & Descrição \\
\hline $\begin{array}{c}\text { Amostragem } \\
\text { aleatória ou casual }\end{array}$ & $\begin{array}{l}\text { É obtida por meio da geração de números aleatórios, ou com a utilização de tabelas de } \\
\text { números aleatórios. }\end{array}$ \\
\hline $\begin{array}{l}\text { Amostragem } \\
\text { sistemática }\end{array}$ & $\begin{array}{l}\text { Os elementos já se encontram em um tipo de ordenação, como, por exemplo, ficha de } \\
\text { servidores em ordem alfabética, notas fiscais organizadas por datas de emissão, etc. } \\
\text { Nesse tipo de seleção, o primeiro elemento deve ser selecionado aleatoriamente e a } \\
\text { partir deste, adota-se uma colocação, como } 20^{\circ}, 40^{\circ}, 60^{\circ} \text {, e assim por diante. }\end{array}$ \\
\hline $\begin{array}{l}\text { Amostragem } \\
\text { proporcional ou } \\
\text { estratificada }\end{array}$ & $\begin{array}{l}\text { A população é segregada dentro de estratos que possuem características homogêneas, } \\
\text { de onde os elementos são escolhidos de forma aleatória, como, por exemplo, setores } \\
\text { de uma empresa, cursos de uma universidade e outros. }\end{array}$ \\
\hline $\begin{array}{c}\text { Amostragem por } \\
\text { conglomerados /lotes }\end{array}$ & $\begin{array}{l}\text { A população é dividida em subgrupos de elementos geograficamente (fisicamente) } \\
\text { próximos. Os conglomerados não possuem necessariamente características } \\
\text { homogêneas, ao contrário do que acontece com a seleção por estratos. São exemplos } \\
\text { desse tipo de amostragem as pessoas em um determinado bairro, os municípios de um } \\
\text { estado, etc. }\end{array}$ \\
\hline Tabela Philips & $\begin{array}{l}\text { Elaborada pela Secretaria Federal de Controle Interno (SFCI), é utilizada para seleção } \\
\text { de amostra e visa à padronização mínima dos procedimentos de auditoria. }\end{array}$ \\
\hline
\end{tabular}

Fonte: Adaptado de Chaves (2010).

Alguns critérios podem ser utilizados para o cálculo da precisão e confiabilidade nos testes de auditoria, como, por exemplo, com aplicação de percentuais pré-estabelecidos, com base na materialidade envolvida, com base no volume das operações e com base na detecção de problemas em trabalhos anteriores; ou ainda, sem critérios expressamente determinados (CUNHA; BEUREN, 2006; CUNHA, BEUREN; HEIN, 2006).

No Brasil, é possível encontrar algumas pesquisas acerca da auditoria. Kroenke et al. (2008) realizaram um estudo em relação aos procedimentos para aplicação da amostragem estatística na auditoria, o qual evidenciou que tal procedimento torna-se imprescindível para que o trabalho do auditor seja considerado confiável.

A pesquisa de Cunha e Beuren (2006) demonstrou que a maioria das empresas de auditoria independente de Santa Catarina não utilizam técnicas estatísticas para a realização de auditoria, presumindo que essa característica é determinada pela escassez de material para orientação dos auditores.

Em matéria de legislação aplicada à auditoria, utilizada para nortear os trabalhos dos profissionais, o trabalho realizado por Castañeda, Carvalho e Lisboa (2007) apresentou uma comparação das normas de auditoria internacionais em relação às normas brasileiras, tendo os autores verificado que, em relação a algumas normas, há uma convergência, enquanto outras normas não possuem qualquer relação. Esse resultado levou os pesquisadores a concluírem que há necessidade de maiores esforços por parte do Brasil para a realização da vislumbrada convergência das normas de auditoria brasileiras em relação às internacionais.

Em outros países, as pesquisas relativas à amostragem na auditoria são realizadas nas mais variadas áreas. Schreiner (2009) descreveu um plano de amostragem para estimar o risco 
de portfólio em microfinanças. Horgan (2003) propôs, em seu trabalho, um novo método de selecionar uma amostra de tamanho fixo de itens distintos, que, segundo o autor, tem benefício por ser de fácil uso, independente do tamanho da amostra.

\title{
3 Métodos e Procedimentos da Pesquisa
}

Quanto aos objetivos, esta pesquisa caracteriza-se como descritiva, a qual, segundo Gil (1999, p. 31), "tem por objetivo descrever as características de determinada população ou fenômeno ou o estabelecimento de relações entre variáveis".

Referente à metodologia, classifica-se, predominantemente, como quantitativa. Para Richardson et al. (1999, p. 70), esse método é evidenciado pela utilização da "quantificação tanto nas modalidades de coleta de informações quanto no tratamento delas por meio de técnicas estatísticas" desde as mais simples, como percentual, média e desvio-padrão; até as mais complexas, como coeficiente de correlação, análise de regressão e outros.

Quanto aos procedimentos, trata-se de um levantamento ou survey. Segundo Gil (1999, p. 35), um survey caracteriza-se

\begin{abstract}
pela interrogação direta das pessoas cujo comportamento se deseja conhecer. Basicamente, procede-se à solicitação de informações a um grupo significativo de pessoas acerca do problema estudado para em seguida, mediante análise quantitativa, obter as conclusões correspondentes aos dados coletados.
\end{abstract}

O universo pesquisado abrangeu 17 unidades de auditoria das Instituições Federais de Ensino Superior, composto de Institutos e Universidades da região Sul do Brasil, coletados no sítio eletrônico do Ministério da Educação (MEC). Os estados do Paraná, Santa Catarina e Rio Grande do Sul foram escolhidos devido à tipicidade e acessibilidade.

$\mathrm{O}$ trabalho de pesquisa apresentou duas limitações a destacar. A primeira consistiu na exclusão, não intencional, da Universidade Federal de Integração Latino-Americana, tendo ocorrido devido à ausência de questionário por falha do envio eletrônico; esse fato, porém, não prejudicou, de forma relevante, o resultado.

Outra limitação do estudo consistiu na aplicação da pesquisa em apenas três áreas da gestão pública, devido à extensão e complexidade de realização em todas as áreas. A escolha das áreas deveu-se à experiência de parte dos autores da pesquisa na área de auditoria, em que verificaram maior volume de recursos humano, material e financeiro envolvidos nas respectivas áreas.

A coleta de dados foi realizada por meio de um questionário disponibilizado por um link na internet, utilizando a ferramenta Google Doc's®, e encaminhado aos responsáveis pelos setores de auditoria interna das IFES por $e$-mail.

As questões abordadas na pesquisa remetiam para consultas sobre os procedimentos adotados na realização de auditorias, ficando estruturadas em dois grupos distintos:

a) aspectos gerais relacionados à auditoria nas IFES;

b) aspectos específicos relacionados à auditoria nas IFES em 2010.

O grupo de aspectos gerais envolvia quatro questões que consultavam sobre (i) percepção dos auditores sobre a área de gestão de maior importância; (ii) área com maior frequência de realização de auditoria nos últimos três anos; (iii) tipo de seleção; e, (iv) método 
de amostragem predominantemente utilizada. As três primeiras perguntas possibilitavam apenas uma opção de resposta, enquanto a última permitia assinalar mais de uma resposta.

As demais questões, referentes ao grupo dos aspectos específicos, consultavam sobre (i) área(s) e subárea(s) de gestão auditada em 2010; (ii) tipo de seleção; e, (iii) método de amostragem predominantemente utilizado nas respectivas áreas. Nesse grupo, apenas o questionamento sobre tipo de seleção permitia somente uma opção de resposta, enquanto os demais possibilitavam assinalar mais de uma resposta.

Para auxiliar na compreensão dos conceitos e no preenchimento das respostas, um glossário pertinente às áreas pesquisadas foi anexado ao questionário. Das 16 unidades de auditoria pesquisadas, 10 responderam à pesquisa. Entretanto, devido à inconsistências nas respostas de uma instituição (não identificada), apenas 9 questionários foram utilizados (terceira limitação da pesquisa), perfazendo uma amostra de 56,25\%. Cabe ressaltar, ainda, que, antes de enviar o questionário às unidades respondentes, foi realizado um pré-teste com auditores internos, que não compuseram a população.

\section{Descrição e Análise dos Dados}

Nesta seção, é apresentada a análise dos dados coletados da pesquisa quanto aos métodos de amostragem utilizados pelas unidades de auditoria interna nas áreas de Gestão de Recursos Humanos, de Gestão Patrimonial e de Gestão de Suprimentos de Bens e Serviços no ano de 2010, além da apresentação de aspectos de caráter geral, relacionados à execução de auditoria.

\subsection{Aspectos Gerais Relacionados à Auditoria nas IFES}

A pesquisa evidenciou que, na percepção dos auditores, a área de Suprimento de Bens e Serviços é a mais importante para realizar auditorias, sendo apontada por $66,67 \%$ dos entrevistados. Provavelmente, a opinião dos auditores corrobore a colocação de Chaves (2010), o qual expõe que essa área é a mais suscetível a falhas e/ou irregularidades. Em seguida, foram apontadas as áreas de Gestão de Recursos Humanos $(22,22 \%)$ e Gestão Patrimonial $(11,11 \%)$.

Quando questionados em relação à área de maior frequência na realização de auditoria entre as áreas pesquisadas, dentro de um período de três anos, a de Suprimentos de Bens e Serviços foi a que obteve maior frequência, sendo apontada por sete das nove instituições respondentes. A área de Recursos Humanos foi citada duas vezes, enquanto que a Patrimonial não foi apontada por nenhuma instituição, ou seja, foi a área que apresentou menor frequência de auditoria em todas as instituições.

Quando questionados quanto ao tipo de seleção predominantemente utilizado para a realização de auditorias, a seleção estatística foi apontada por 5 das 9 instituições. Esse resultado não converge com o apresentado em 2010, uma vez que a seleção não estatística prevaleceu para a auditoria nas áreas de Gestão de Recursos Humanos e Patrimonial; enquanto que, na área de Gestão de Suprimento de Bens e Serviços, houve utilização de ambos os tipos de seleção em igual número. Cabe ressaltar que essa divergência origina-se das respostas de uma instituição, a qual, apesar de ter respondido que de modo geral utiliza a seleção estatística, aplicou a seleção não estatística nos trabalhos realizados em 2010. 
Em relação aos métodos de amostragem predominantemente utilizados, a amostragem sistemática e a Tabela Philips foram as mais utilizadas, enquanto as amostragens aleatória simples e estratificada foram apontadas uma única vez, conforme Tabela 1.

Tabela 1 - Métodos de amostragem predominantemente utilizados

\begin{tabular}{l|c}
\hline \multicolumn{1}{c|}{ Métodos } & N. de IFES \\
\hline Aleatória Simples & 1 \\
\hline Sistemática & 2 \\
\hline Estratificada & 1 \\
\hline Tabela Philips & 2 \\
\hline Amostragem por Conglomerados ou Lotes & 0 \\
\hline
\end{tabular}

Fonte: Dados da pesquisa.

Pode-se observar que a amostragem por conglomerados ou lotes não foi apontada por nenhuma das instituições.

\subsection{Aspectos Específicos Relacionados à Auditoria nas IFES em 2010}

A pesquisa permitiu identificar que, no ano de 2010, entre as nove unidades de auditoria respondentes, as áreas auditadas foram apontadas conforme distribuição do Gráfico 1:

\section{Gráfico 1 - Áreas de Gestão auditadas em 2010 nas IFES}

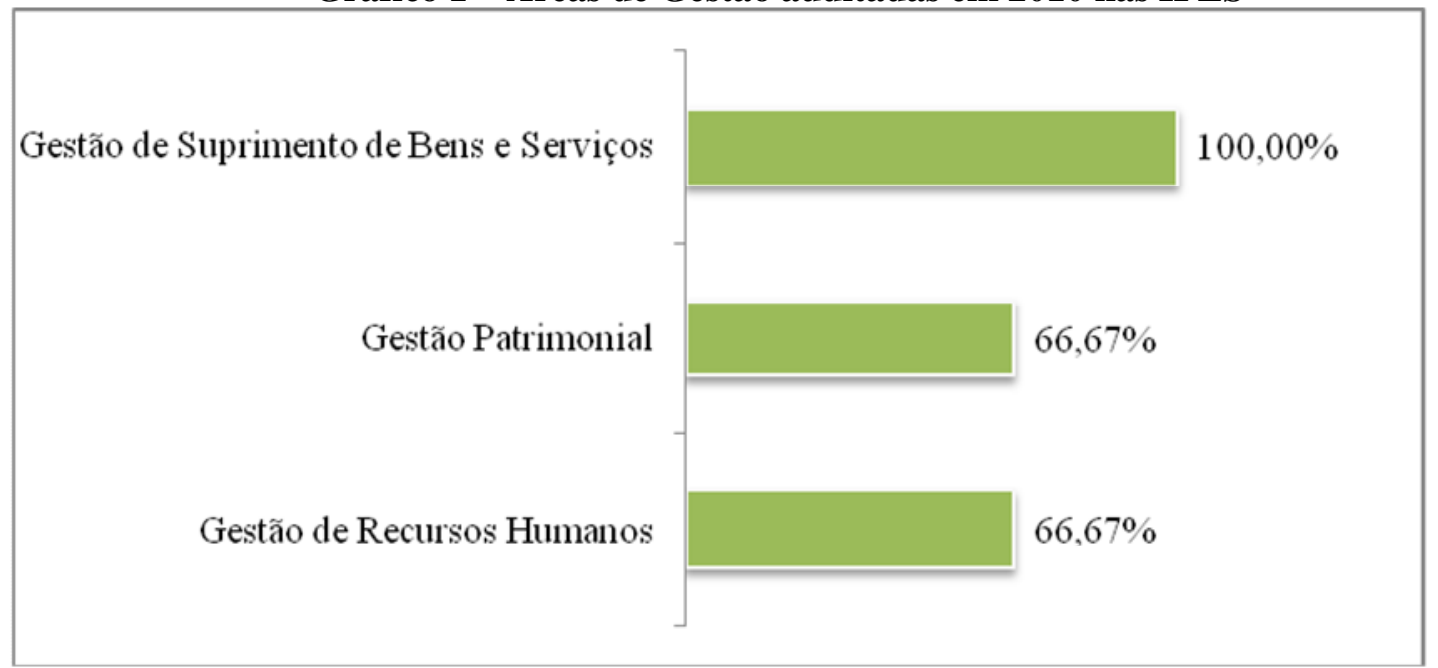

Fonte: Dados da pesquisa.

Observa-se que $100 \%$ das instituições (9 unidades) realizaram auditoria na área do Suprimento de Bens e Serviços em 2010. As outras áreas, Gestão de Recursos Humanos e Patrimonial, foram auditadas por 6 entidades, representando $66,67 \%$ da amostra.

A Tabela 2 apresenta a quantidade de instituições que realizaram auditoria por área, bem como a quantidade total de trabalhos realizados em 2010. 
A auditoria e os procedimentos de amostragem nas instituições federais de ensino superior da região sul do...

Tabela 2 - Auditorias realizadas pelas IFES e quantidade de trabalhos realizados

\begin{tabular}{l|c|c|c}
\hline \multicolumn{1}{c|}{$\begin{array}{c}\text { Trabalhos realizados } \\
\text { em 2010 }\end{array}$} & $\begin{array}{c}\text { Gestão de Recursos } \\
\text { Humanos }\end{array}$ & $\begin{array}{c}\text { Gestão } \\
\text { Patrimonial }\end{array}$ & $\begin{array}{c}\text { Gestão de Suprimento de } \\
\text { Bens e Serviços }\end{array}$ \\
\hline $\begin{array}{l}\text { Número de IFES que } \\
\text { realizaram auditoria }\end{array}$ & 6 & 6 & 9 \\
\hline $\begin{array}{l}\text { Número de auditorias } \\
\text { realizadas }\end{array}$ & 17 & 19 & 25 \\
\hline
\end{tabular}

Fonte: Dados da pesquisa.

Conforme pode ser observado, a área de Gestão de Suprimento de Bens e Serviços foi a mais auditada, e, consequentemente, foi a área que recebeu maior quantidade de auditorias com 25 trabalhos realizados; enquanto, na área de Gestão de RH e na área de Gestão Patrimonial, a quantidade de trabalhos foi de 17 e 19, respectivamente.

\subsubsection{Auditoria na Área de Gestão de Recursos Humanos em 2010}

Foram realizadas 17 auditorias na área de Gestão de Recursos Humanos. A subárea de Remuneração, Benefícios e Vantagens obteve um percentual de $29,41 \%$, sendo apontada por cinco das nove entidades (Tabela 3). Em seguida, as subáreas Indenizações e Movimentação foram responsáveis por $23,52 \%$ e $17,64 \%$ das auditorias realizadas, respectivamente. As subáreas Seguridade Social e de Regime Disciplinar foram apontadas por duas unidades de auditoria $(11,76 \%)$.

A opção "outras subáreas" foi apontada por uma instituição, a qual respondeu que realizou auditoria em Controle de Frequência e na Acumulação de Cargos, além da subárea Remuneração, Benefícios e Vantagens e da subárea Indenizações.

Tabela 3 - Subáreas de Gestão de RH auditadas em 2010

\begin{tabular}{l|c|c}
\hline Subáreas de Gestão de Recursos Humanos & \% de Auditorias & N. de Auditoria/IFES \\
\hline Movimentação & 17,64 & 3 \\
\hline Remuneração, Benefícios e Vantagens & 29,41 & 5 \\
\hline Indenizações & 23,52 & 4 \\
\hline Seguridade Social & 11,76 & 2 \\
\hline Regime Disciplinar & 11,76 & 1 \\
\hline $\begin{array}{l}\text { Outras subáreas - Controle de } \\
\text { frequência/acumulação de cargos }\end{array}$ & 5,88 & 0 \\
\hline Capacitação e Desenvolvimento & 0,00 & $\mathbf{1 7}$ \\
\hline Total & $\mathbf{1 0 0 , 0 0}$ & 2 \\
\hline
\end{tabular}

Fonte: Dados da pesquisa.

Cabe destacar que a subárea Capacitação e Desenvolvimento não foi citada por nenhuma instituição, embora o Decreto n. 5.707/2006 tenha regulamentado a Política e as Diretrizes para o Desenvolvimento do Pessoal da administração pública federal direta, autárquica e fundacional.

Quando questionadas em relação ao tipo de seleção utilizado nas auditorias, a Tabela 4 demonstra que quatro instituições utilizaram seleção não estatística; uma unidade respondeu ter utilizado a seleção por método estatístico; e uma unidade $(16,67 \%)$ respondeu não utilizar nenhum tipo de seleção. 
Tabela 4 - Tipo de seleção utilizada em auditoria(s) de Gestão de RH em 2010

\begin{tabular}{l|c}
\multicolumn{1}{c|}{ Tipo de seleção } & \% IFES \\
\hline Seleção estatística & 16,67 \\
\hline Seleção não estatística & 66,67 \\
\hline $\begin{array}{l}\text { Não utilizamos seleção na realização de Auditoria na área de } \\
\text { Gestão de Recursos Humanos em 2010 }\end{array}$ & 16,67 \\
\hline Total & $\mathbf{1 0 0 , 0 0}$ \\
\hline
\end{tabular}

Fonte: Dados da pesquisa.

Em relação à utilização dos métodos de amostragem, se observou:

- aleatória simples, sistemática e Tabela Philips - apenas 1 apontamento por diferentes instituições;

- amostragem estratificada e por conglomerados/lotes - não foram utilizados para realização de auditorias nessa área; e ainda, uma das IFES não utilizou amostragem em seus trabalhos.

Os critérios utilizados para o cálculo da precisão e confiabilidade nos testes de auditoria pelas instituições foram:

- Com base no volume das operações/Com base na detecção de problemas em trabalhos anteriores e não expressamente determinados - apontados por uma instituição cada.

- Com base na materialidade envolvida - apontado por duas instituições.

O critério com aplicação de percentuais pré-estabelecidos não foi utilizado por nenhuma unidade.

\subsubsection{Auditoria na Área de Gestão Patrimonial nas IFES em 2010}

Foram realizadas 19 auditorias na área de Gestão Patrimonial. A subárea de Inventários Físicos e Financeiros foi a que mais recebeu auditoria em 2010, sendo apontada por seis instituições pesquisadas (31,57\%). A subárea Bens Imobiliários e Bens Móveis e Equipamentos representaram um percentual de $26,31 \%$, sendo apontada por cinco instituições cada uma (Tabela 5). A pesquisa também demonstrou que a subárea Meios de Transporte foi apontada por duas instituições $(10,52 \%)$, e a subárea Investimentos Permanentes recebeu auditoria em apenas uma das instituições $(5,26 \%)$. Salienta-se que as subáreas Recursos Naturais, Bens Agropecuários e Acervo de Bens Culturais não receberam auditoria em 2010.

Tabela 5 - Subáreas de Gestão Patrimonial auditadas em 2010

\begin{tabular}{l|c|c}
\hline \multicolumn{1}{c|}{ Subáreas de Gestão Patrimonial } & \% de Auditorias & N. de Auditorias/IFES \\
\hline Inventários Físicos e Financeiros & 31,57 & 6 \\
\hline Bens Imobiliários & 26,31 & 5 \\
\hline Bens Naturais & 0,00 & 0 \\
\hline Meios de Transportes & 10,52 & 2 \\
\hline Bens Móveis e Equipamentos & 26,31 & 5 \\
\hline Bens Agropecuários & 0,00 & 0 \\
\hline Acervo de Bens Culturais & 0,00 & 0 \\
\hline Bens Intangíveis & 0,00 & 0 \\
\hline Investimentos Permanentes & 5,26 & 1 \\
\hline Total & $\mathbf{1 0 0 , 0 0}$ & $\mathbf{1 9}$ \\
\hline
\end{tabular}

Fonte: Dados da pesquisa.

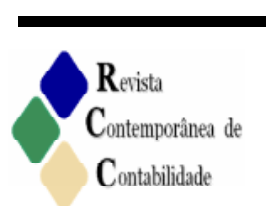


Cabe destaque para a área de Bens Intangíveis, que, embora haja previsão para mensuração dessa classe de Ativo na NBC T 16.10 e a correspondente amortização na NBC T 16.9, ambas vigentes desde janeiro de 2010, ainda não é foco das auditorias internas pesquisadas.

A maioria das instituições que realizaram auditoria na área de Gestão Patrimonial utilizou a seleção não estatística em seus trabalhos no ano de 2010 (Tabela 6). Das seis unidades, cinco apontaram ter utilizado esse tipo de seleção, e uma unidade apontou a seleção estatística.

Tabela 6 - Tipo de seleção utilizada em auditoria(s) na Gestão Patrimonial em 2010

\begin{tabular}{l|c}
\multicolumn{1}{c|}{ Tipo de seleção } & \% IFES \\
\hline Seleção estatística & 16,67 \\
\hline Seleção não estatística & 83,33 \\
\hline Total & $\mathbf{1 0 0 , 0 0}$ \\
\hline Fonte: Dados da pesquisa.
\end{tabular}

Quanto aos métodos de amostragem utilizados para a realização de auditorias na área de Gestão Patrimonial, a distribuição apresentou-se da seguinte maneira:

- Aleatória simples / Tabela Philips - apontadas por duas instituições cada.

- Sistemática - apontada por uma instituição.

Os métodos de amostragem estratificada e por conglomerados/lotes não foram utilizados pelas instituições pesquisadas nas auditorias em 2010 para a área de Gestão Patrimonial.

Quanto aos critérios utilizados para o cálculo da precisão e confiabilidade nos testes de auditoria pelas instituições foram:

- Com base na materialidade envolvida - duas instituições.

- Com base na detecção de problemas em trabalhos anteriores - uma instituição.

Ressalta-se que não foram citados os critérios: com aplicação de percentuais préestabelecidos, não expressamente determinados e com base no volume de operações.

\subsubsection{Auditoria na Área de Gestão de Suprimento de Bens e Serviços em 2010}

Foram realizadas 25 auditorias na área de Gestão de Suprimento de Bens e Serviços, sendo essa área auditada por $100 \%$ das instituições respondentes. Dentre as subáreas, a de Processos Licitatórios foi a mais auditada $(47,06 \%)$, sendo apontada por oito instituições (Tabela 7). Cabe salientar que uma das unidades afirmou não ter realizado auditoria nas subáreas relacionadas no questionário, todavia não informou qual subárea foi auditada em seus trabalhos.

Também ficou demonstrado que seis unidades realizaram auditoria na subárea de Contratos de Obras, Compras e Serviços (35,29\%); a subárea de Convênios de Obras e Serviços e a de Gerenciamento de Estoques foram apontadas por número igual de instituições (cinco unidades). Por fim, a subárea de Contratos de Franquias, Concessão de Permissão não foi apontada por nenhuma das unidades. 
Tabela 7 - Subáreas de Suprimento de Bens e Serviços auditadas em 2010

\begin{tabular}{l|c|c}
\hline Subáreas de Gestão de Suprimento de Bens e Serviços & $\begin{array}{c}\text { \% de } \\
\text { Auditorias }\end{array}$ & N. de Auditorias/IFES \\
\hline Processos Licitatórios & 47,06 & 8 \\
\hline Contratos de Obras, Compras e Serviços & 35,29 & 6 \\
\hline Convênios de Obras e Serviços & 29,41 & 5 \\
\hline Gerenciamento de Estoques & 29,41 & 5 \\
\hline Contratos de Franquia, Concessão ou Permissão & 0,00 & 0 \\
\hline Outras Subáreas - não informadas & 5,88 & 1 \\
\hline Total & $\mathbf{1 0 0 , 0 0}$ & $\mathbf{2 5}$ \\
\hline
\end{tabular}

Fonte: Dados da pesquisa.

Dentre os tipos de seleção informados pelas IFES na área de Gestão de Suprimento de Bens e Serviços, apenas uma unidade apontou não ter utilizado seleção na realização das auditorias em 2010.

A Tabela 8 ilustra que a seleção não estatística e a seleção estatística foram apontadas em igual número por quatro instituições, representando um percentual aproximado de $45 \%$.

Tabela 8 - Tipo de seleção utilizada na realização de auditoria(s) na Gestão de Suprimento de Bens e Serviços em 2010

\begin{tabular}{l|c}
\hline \multicolumn{1}{c|}{ Tipo de seleção } & \% IFES \\
\hline Seleção estatística & 45 \\
\hline Seleção não estatística & 45 \\
\hline $\begin{array}{l}\text { Não utilizamos seleção na realização de Auditoria na } \\
\text { área de Gestão Patrimonial em 2010 }\end{array}$ & 10 \\
\hline Total & $\mathbf{1 0 0}$ \\
\hline
\end{tabular}

Fonte: Dados da pesquisa.

Os métodos de amostragem utilizados na realização de auditoria foram evidenciadas: - Aleatória simples / Estratificada / Tabela Philips - apontadas por uma instituição cada.

- Sistemática - duas instituições. utilizado.

Segundo os respondentes, o método de amostragem por conglomerados/lotes não foi

Quanto aos critérios utilizados para o cálculo da precisão e confiabilidade nos testes de auditoria pelas instituições foram:

- Com aplicação de percentuais pré-estabelecidos / Com base no volume das operações apontadas por uma instituição cada.

- Com base na materialidade envolvida - quatro instituições.

- Com base na detecção de problemas em trabalhos anteriores - duas instituições.

Cabe destacar que o critério não expressamente determinado não foi apontado por nenhuma das instituições.

Considerando as três áreas pesquisadas, observa-se que a predominância da utilização de seleção não estatística para determinação de amostragem no ano de 2010 não é exclusividade do setor público. A evidência encontrada no resultado da pesquisa converge com o apresentado por Cunha e Beuren (2006, p. 79) quando pesquisaram técnicas de amostragem utilizadas nas empresas de auditoria independente, estabelecidas em Santa 
Catarina, na qual afirmaram que "a maioria dos auditores se utilizam da subjetividade, fundamentada na experiência profissional adquirida durante os anos de auditoria para determinação da amostra".

Também pode ser verificado que a área de Gestão de Suprimento de Bens e Serviços é a mais auditada pelas unidades de auditoria pesquisadas; provavelmente por se relacionar com a teoria defendida por Chaves (2010) de que é uma área complexa da gestão pública, em que há relação de gestores públicos com empresas privadas, e quando princípios como legalidade, impessoalidade, moralidade, igualdade, probidade administrativa e outros, dispostos pela "lei das licitações", se tornam vitais para a gestão eficiente dos recursos públicos (BRASIL, Lei n. 8.666/93).

Outra questão verificada relaciona-se a subáreas não auditadas. Uma delas é a subárea de Capacitação e Desenvolvimento (Gestão de RH), embora haja a regulamentação do Decreto n. 5.707/2006. Outra subárea não auditada foi Bens Intangíveis (Gestão Patrimonial), que pode estar relacionado ao fato de que a Contabilidade Pública está passando por uma convergência das normas brasileiras às internacionais, incluindo a mensuração e contabilização, conforme disposto pela NBC T 16.10, vigente desde janeiro de 2010, sendo necessário entendimento das novas regras para poder realizar auditoria.

A seleção não estatística foi utilizada em duas das três áreas pesquisadas e difere da estatística, pois possibilita ao auditor conhecer o risco ao emitir seu parecer, conforme defendido por Cunha, Beuren e Hein (2006). A opção de escolha do uso de amostragem não estatística pode estar relacionada ao desconhecimento de ferramentas estatísticas, o que acarreta a necessidade de aprimoramento e capacitação continuada, a exemplo do que acontece com os auditores independentes.

\section{Considerações Finais}

A auditoria governamental tem, na sua essência, o controle exercido nas áreas da gestão pública. E esta pesquisa, envolvendo as unidades de auditoria das Instituições Federais de Ensino Superior (IFES), demonstrou que esse controle é realizado por meio de procedimentos, tais como: técnicas de seleção, métodos de amostragem e critérios para o cálculo de precisão e confiabilidade dos testes de auditoria nas áreas de delimitação do estudo (Gestão de RH, Gestão Patrimonial e de Gestão de Suprimento de Bens e Serviços).

A área de Gestão de Suprimento de Bens e Serviços foi apontada como a área de maior frequência na realização de auditorias, o que corrobora com a percepção dos auditores quanto à área de maior importância e sinaliza que a prática converge com a teoria, sendo apontada como a área de maior complexidade.

Especificamente em relação aos dados obtidos acerca das auditorias realizadas em 2010, os métodos de amostragem mais utilizados foram: amostragem aleatória simples, sistemática e Tabela Philips; e os critérios com base na materialidade envolvida e com base na detecção de trabalhos anteriores foram os mais utilizados para cálculo da precisão e confiabilidade dos testes de auditoria.

Ainda em relação ao ano de 2010, observou-se o predomínio da seleção não estatística para determinação de amostragem, convergindo com o trabalho apresentado por Cunha e Beuren (2006, p. 79) em relação às técnicas utilizadas pelas empresas de auditoria independente, estabelecidas em Santa Catarina. 
Cabe verificar, no entanto, quais os fatores originários dessa característica, a fim de identificar se os profissionais das auditorias internas das IFES possuem estrutura e suporte necessários em termos de capacitação e atualização dos conhecimentos, uma vez que Kroenke et al. (2008) defendem que a amostragem estatística torna-se imprescindível para que o trabalho do auditor seja considerado confiável.

Verificou-se que algumas subáreas não foram auditadas, embora haja legislação disciplinando esses assuntos, como, por exemplo, a subárea de Capacitação e Desenvolvimento, normatizada pelo Decreto n. 5.707/2006. Outra subárea não auditada foi a de Bens Intangíveis, cuja classe de Ativos é normatizada quanto à mensuração e amortização por meio das NBC T 16.10 e 16.9, respectivamente, vigentes desde janeiro de 2010.

Resta sugerir a realização de pesquisas para detectar o motivo da utilização não estatística em detrimento da amostragem estatística, uma vez que os métodos estatísticos são vislumbrados como mais confiáveis, adequados e imparciais. Outra possibilidade de pesquisa se vislumbra em averiguar se o nível de adequação necessária está sendo atendido para o efetivo trabalho da auditoria interna nas IFES, como capacitação continuada, aprimoramento dos procedimentos de auditoria.

Também se sugere estender essa pesquisa a todas as Instituições Federais de Ensino Superior brasileiras, a fim de investigar se os resultados apresentam-se em consonância com os obtidos neste trabalho. E, por fim, sugere-se realizar a pesquisa considerando um espaço de tempo maior, tendo por objetivo analisar se existe homogeneidade na realização de auditoria no decorrer do tempo.

\section{Referências}

BOYNTON, W. C.; JOHNSON, R. N.; KELL, W. G. Auditoria. Tradução José Evaristo dos Santos. São Paulo: Atlas, 2002.

BRASIL. Constituição Federal de 1988. Constituição da República Federativa do Brasil: promulgada em 5 de outubro de 1988. Disponível em: <http://www4.planalto.gov.br/ legislacao>. Acesso em: 4 abr. 2011.

BRASIL. Lei n. 8.666, de 21 de junho de 1993. Regulamenta o art. 37, inciso XXI, da Constituição Federal, institui normas para licitações e contratos da Administração Pública e dá outras providências. Disponível em: <http://www.planalto.gov.br/ccivil_03/leis/L8666 cons.htm>. Acesso em 18 ago. 2012.

BRASIL. Decreto n. 3.591, de 06 de setembro de 2000. Dispõe sobre o Sistema de Controle Interno do Poder Executivo Federal e dá outras providências. Disponível em: <http://www.planalto.gov.br/ccivil_03/decreto/D3591.htm>. Acesso em 4 jul. 2011.

BRASIL. Decreto n. 5.707, de 23 de fevereiro de 2006. Institui a Política e as Diretrizes para o Desenvolvimento de Pessoal da administração pública federal direta, autárquica e fundacional, e regulamenta dispositivos da Lei $\mathrm{n}^{\circ}$. 8.112, de 11 de dezembro de 1990. Disponível em: <http://www.planalto.gov.br/ccivil_03/_Ato2004-2006/2006/Decreto/D5707 .htm>. Acesso em 10 jul. 2011. 
BRASIL. Decreto-Lei n. 200, de 25 de fevereiro de 1967. Dispõe sobre a organização da Administração Federal, estabelece diretrizes para a Reforma Administrativa e dá outras providências. Disponível em: http://www.planalto.gov.br/ccivil_03/decreto-lei/Del0200. htm>. Acesso em: 4 jul. 2011.

BRASIL. Instrução Normativa n. 01, de 6 de abril de 2001. Ministério da Fazenda Secretaria Federal de Controle Interno (SFCI). Define diretrizes, princípios, conceitos e aprova normas técnicas para a atuação do Sistema de Controle Interno do Poder Executivo Federal. Disponível em: http://www.cgu.gov.br/Legislacao/Arquivos/InstrucoesNormativas /IN01_06abr2001.pdf>. Acesso em: 4 jul. 2011.

CASTAÑEDA, B. E. G.; CARVAlHO, L. N. G.; LISBOA, N. P. Comparação entre as Normas de Auditoria do Brasil e as Internacionais (IAASB). Revista Contemporânea de Contabilidade - RCC, Florianópolis/SC, n. 7, p. 81-100, jan./jun. 2007.

CHAVES, R. S. Auditoria e Controladoria no Setor Público: fortalecimento dos controles internos com jurisprudência do TCU. 1 ed. Curitiba: Juruá Editora, 2010.

CONSELHO FEDERAL DE CONTABILIDADE. Resolução CFC n. 1.222, de 27 de novembro de 2009. Aprova a NBC TA 530 - "Amostragem em Auditoria", elaborada de acordo com a sua equivalente internacional ISA 530. Disponível em: <http://www.normaslegais.com.br/ legislacao/resolucaocfc1222_2009.htm>. Acesso em: 20 set. 2011.

CONSELHO FEDERAL DE CONTABILIDADE. Resolução CFC n. 986, de 21 de novembro de 2003. Aprova a NBC TI 01 - Da Auditoria Interna. Disponível em: <http://www.cfc.org.br/sisweb/sre/detalhes_sre.aspx? Codigo=2003/000986>. Acesso em: 20 set. 2011.

CONSELHO FEDERAL DE CONTABILIDADE. Resolução CFC n. 1.136, de 21 de novembro de 2008. Aprova a NBC T 16.9 - Depreciação, Amortização e Exaustão. Disponível em: <http://www.tesouro.fazenda.gov.br/contabilidade_governamental/download/RES_CFC_ 11362008_NBC_T169_Depreciacao_Amortizacao_Exaustao.pdf >. Acesso em: 25 ago. 2012.

CONSELHO FEDERAL DE CONTABILIDADE. Resolução CFC n. 1.137, de 21 de novembro de 2008. Aprova a NBC T 16.10 - Avaliação e Mensuração de Ativos e Passivos em Entidades do Setor Público. Disponível em: <http://www.tesouro.fazenda.gov.br/contabilidade_governamental/download/RES_CFC1137 2008_NBC_T1610_Aval_Mensur_Ativos_Passivos_Entidades_Setor_Publico.pdf $>$. Acesso em: 25 ago. 2012.

COOPERS, W. P. Amostragem em Auditoria: série de guias de auditoria - a auditoria de Price Waterhouse Coopers, 1985.

COSTA, A. F.; PEREIRA, J. M., BLANCO, S. R. Auditoria do Sector Público no contexto da nova gestão pública. Polytechnical Studies Review - TEKHNÉ, IPCA (Instituto Politécnico do Cávado e do Ave), n. 5/6, p. 2021-225, 2006.

CUNHA, P. R. da; BEUREN, I. M. Técnicas de Amostragem Utilizadas nas Empresas de Auditoria Independente Estabelecidas em Santa Catarina. Revista Contabilidade \& Finanças - USP, São Paulo, n. 40, p. 67 - 86, jan./abr. 2006. 
CUNHA, P. R. da; BERUREN, I. M.; HEIN, N. Técnicas de Amostragem Utilizadas nas Empresas de Auditoria Independente Estabelecidas em Santa Catarina Versus na Cidade do Rio de Janeiro. UnB Contábil - UNB, Brasília, vol. 9, n. 1, jan./jun. 2006.

GIL, A. C. Métodos e técnicas de pesquisa social. 5. ed. São Paulo: Atlas, 1999

INSTITUTO RUI BARBOSA. Normas de Auditoria Governamental - NAGs: Aplicáveis ao Controle Externo. 88 p. 2010. Disponível em: http://www.controlepublico.org.br/files/ Proposta-de-Anteprojeto-NAGs_24-11.pdf. Acesso em: 20 ago. 2012.

HORGAN, J. M. A list-sequential sampling scheme with applications in financial auditing. Journal of Management Mathematics - IMA, n. 14, p. 31-48, 2003.

KROENKE et al. Procedimentos para aplicação da amostragem estatística na auditoria. In: SEMEAD, 11., 2008, São Paulo/SP. Anais... São Paulo: SEMEAD, 2008.

MINISTÉRIO DA EDUCAÇÃO (MEC). Instituições de Educação Superior e Cursos Cadastrados. Disponível em: <http://emec.mec.gov.br/>. Acesso em: 30 set. 2011.

PETER, M. G. A.; MACHADO, M. V. V. Manual de Auditoria Governamental. 1 ed. São Paulo: Atlas, 2009.

RICHARDSON, R. J. Pesquisa social: métodos e técnicas. 3 ed. São Paulo: Atlas, 1999

SANTOS, J.; DINIZ, J. A.; CORRAR, L. J. O foco é a teoria amostral nos campos de auditoria contábil tradicional e da auditoria digital: testando a lei Newcomb-Benford para o primeiro dígito nas contas públicas. Brazilian Business Review - BBR, Vitória, n. 01, p. 7189, jan./jun. 2005.

SCHREINER, M. Statistical audit sampling for portfolio-at-risk in microfinance. Managerial Finance, n. 12, p. 990-998, 2009. 